\title{
Active Braking of an Electronic Brake Booster Facing Intelligent Automobile
}

\author{
Jian $\mathrm{Wu}^{\mathrm{a}}{ }^{\mathrm{a}}$, Pengcheng Chen ${ }^{\mathrm{b}}$, Jian Zhao ${ }^{\mathrm{a}}$, and Rui $\mathrm{He}^{\mathrm{b}}$ \\ a Jilin University, Changchun, 130022, China \\ ${ }^{b}$ State Key Lab of ASCL, Changchun, 130022, China
}

\begin{abstract}
In this paper, a novel electronic brake booster and an accurate pressure control method for engineering are put forward and consider the shortcomings of the existing braking system in active braking for intelligent driving. Together with the hydraulic control unit, they are comprised of two working modes: active braking for automatic drive and passive braking for driver intervention. For wheel cylinder pressure control, we translate the control problem of pressure to position tracking. The strong nonlinearity and the load-dependent friction make the position tracking control of the electro-mechanical brake booster more challenging. Consequently, a modified PI control architecture is presented with techniques of cascaded three closed loop PI controller, friction compensation based on friction model, and gain scheduling. Finally, based on dSPACE, we carried out the rapid prototyping tests of active braking and hardware in the loop tests covering full speed ACC conditions. The results show that pressure control, acceleration control, and speed control achieve optimal performance.
\end{abstract}

Keywords: intelligent automobile; electric brake booster; active brake; accurate pressure control; hardware in the loop

(Submitted on May 16, 2018; Revised on June 27, 2018; Accepted on July 22, 2018)

(C) 2018 Totem Publisher, Inc. All rights reserved.

\section{Introduction}

Automotive intelligentization is a significant developmental direction for the automobile industry. Driven by many years of research, intelligent assistant driving technology under simple working conditions is emerging. However, most automatic driving vehicles are not absolutely reliable due to their braking systems, and the higher level automatic driving vehicles (L4 or L5) require double failure-backup for their braking systems [1]. Therefore, intelligent braking systems with high reliability and robustness are the key issues for the implementation of intelligent driving technology.

The longitudinal anti-collision system is an important function of intelligent driving. Accidents in which rear-end crashes or front/side impacts are involved cause thousands of injuries and fatalities every year. The performance of braking systems plays a decisive role in reducing traffic accidents. However, on the one hand, the traditional brake system (vacuum brake booster) is a kind of servo device, which cannot be utilized well in the context of automatic braking or active braking. On the other hand, the ESC system, which is used for the ACC and AEB functions, is weak in speed when pressure increases and weak in continuous work time [2]. It is far from expected performance requirements for a reliable, highperformance longitudinal collision system. Because a high-performance braking actuator plays a significant role in improving the safety of vehicles, the development of intelligent active or automate braking systems and a related pressure control algorithm is of great significance.

The active braking of the existing intelligent driving vehicle is realized by the electronic stability control system (ESC) [3]. The working principle of this function is to close the change-over valve, to open the pre-charge valve, and to use the dc motor and the plunger pump to realize the active pressure rise. The actuator is limited by the pump oil capacity of the DC motor in the context of the increasing pressure speed, and it is limited by the power-on time of the solenoid valve in the context of continuous work time. Additionally, for the AEB demand of large braking deceleration, the low power DC motor

\footnotetext{
* Corresponding author.

E-mail address: wujian@jlu.edu.cn
} 
cannot be satisfied. The brake-by-wire system, represented by EHB and EMB, is a well-controlled scheme that achieves good performance in linear control and pressure decoupling. However, the piping layout and control methods are complex. The electromagnetic valve is affected by temperature, and the electromagnetic characteristics are unstable, so the accuracy of pressure control during continuous pressure-building is reduced. The issue of the $42 \mathrm{~V}$ power supply and non-backup in electronic mechanical brakes results in its poor performance in the market [4]. The electronic brake booster, represented by iBooster, is widely used in intelligent driving and pure electric vehicles. The structural scheme of iBooster is a chassis brake system that can be summarized as an actuation module powered by PMSM, a power supply module based on vehicle battery, a modulation of ESP or ESP hev, and a foundation module for brake actuators [5]. The electronic brake system meets the demands of the modern vehicle, but the actuator is less integrated. At the same time, the automobile parts manufacturer such as the Continental, the Toyota Corporation, and the TRW have launched the braking system for intelligent driving and electric vehicles. Its active braking function is an important issue for further development in the automotive industry [6-8].

In view of the present situation of the chassis brake system's lack of active braking ability and a single function, a novel intelligent electronic brake system is designed, and a precise control method of wheel cylinder pressure based on the electronic brake system is put forward in this paper. The new intelligent electronic brake booster is composed of the permanent magnet synchronous motor, gear and ball screw, the serve body, reaction disc, input rod, and output rod. The power supply of the brake booster is provided by the permanent magnet synchronous motor. On the one hand, the speed of response is faster, which ensures the pressure build-up rate under the emergency braking condition. On the other hand, the continuous operation capability of the solenoid valve is strong enough to meet the needs of the adaptive cruise system for extended periods of time.

The accurate control of the wheel cylinder pressure is the key problem of active brakes for the intelligent electronic brake, and it is also the basis of the comfort and safety of the adaptive cruise control system. This paper presents a nonlinear pressure control method based on the novel brake booster and the upper ADAS system's requirements. In the field of pressure control, a direct force control structure is given in [9]. A pressure control strategy based on solenoid valve characteristics is presented in [10], and an adaptive position pressure control method is proposed in [11]. However, due to the factors of hydraulic lag and friction, controlling the target pressure directly will make the control effect delayed and overshoot seriously for such an electro-mechanical hydraulic system. Based on the pressure control method mentioned above, the electro-hydraulic system is hierarchically controlled in this paper, and the control target of pressure is decomposed into the structure of pressure-position-speed-current. Thus, this paper translates the problem of pressure control to position. On the basis of the traditional three-loop PI controller of PMSM, combined with feedforward compensation and variable gain technology, the wheel cylinder pressure is dealt with using a cascade, adaptive PI controller and friction compensation control system. The experimental results show that the controller satisfies the pressure demand of the strong nonlinear electromechanical system.

\section{System Description of Active Brake Actuator}

The lateral control and longitudinal control actuators of an automatic driving vehicle are shown in Figure 1. The electronic power steering system is responsible for automatic steering, and the electronic brake system is the actuator of automatic braking. A novel electronic brake booster system is significant.

\subsection{Introduction of the Electronic Brake Booster Mechanism}

The schematic graph of the integrated electronic brake system is shown in Figure 2. Such an electronic-mechanicalhydraulic system mainly includes the electric brake booster and the hydraulic control unit.

The electric brake booster consists of a permanent magnet synchronous motor (PMSM), gears, ball screw, servo body, motor angle sensor and current sensor, and reaction disk. The first-state reduction includes a pinion and a gear. The pinion is connected to the shaft of the dc motor, and the gear is connected to the screw nut rigidly. The second-state reduction is achieved by the ball screw. The PMSM, as the power source of the assist actuator, is embedded in the interior of the integrated electromechanical brake booster. The ball screw transfers the rotational motion of the motor to linear motion together with gears. The motor angle sensor and current sensor are used for the position control of the PMSM. With the input rod, it has a direct connection to the driver via the brake pedal. By using the angle sensor, the electro-mechanical brake booster determines the driver brake request for the pedal force boost. The necessary boost force is calculated based on the determined driver brake request and a specific project defined boost characteristic. Thus, the servo body cooperates with the input rod to push the reaction disk under the action of the motor. The output rod is connected to the first piston of the master cylinder, as the result of generating pressure. The hydraulic control unit consists of 12 solenoid valves, two plunger 
pumps, two low-pressure accumulators, a dc motor, and some non-return valves. The main function of the HCU is pressure regulation and partial pressure decoupling.

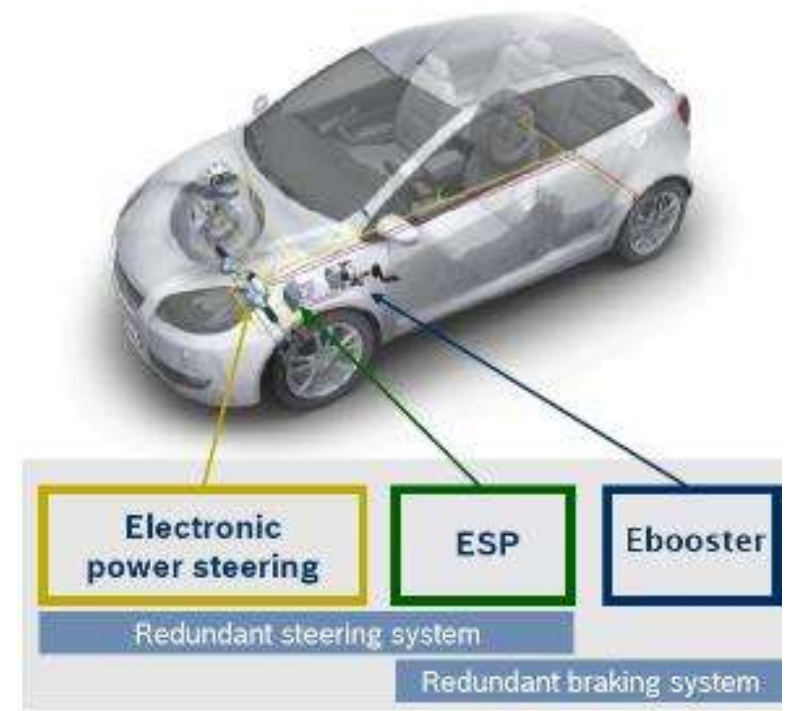

Figure 1. The automatic steering and braking actuator

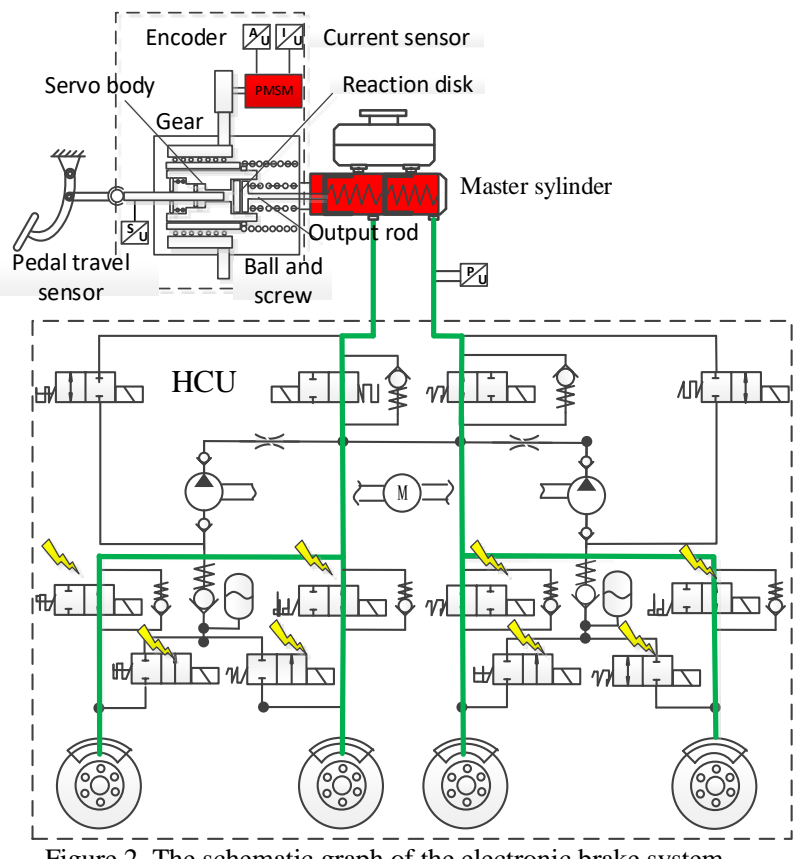

Figure 2. The schematic graph of the electronic brake system

There are two working modes for the intelligent electronic brake booster. When the passive brake is applied, the motor torque is used as a booster device to provide auxiliary braking for manpower. Under this working mode, it serves as the brake booster function, and the transmission route of force is the coupling of manpower and motor force on the reaction disc; it acts on output putter in parallel. The second mode of the electric brake booster is the active braking mode, where the manpower does not participate in the braking process in this mode. As a pure power supply device, the motor provides the braking force for the whole braking system. The transmission route of motor torque is acting on the output rod by the reaction disc directly, forming the braking pressure in the main cylinder. Under this mode of work, the solenoid valves are working. When the ABS intervenes, the working mode is consistent with the conventional passive brake ABS intervention; that is, the inlet valve of the lock wheels are properly closed, the outlet valves open, and the motor will pump the oil back to the master cylinder. 


\subsection{Active Braking Control Method Stating}

In the hydraulic brake system, the hydraulic dynamics of the master cylinder and wheel cylinders can be described by a PV curve. The hydraulic volume $\mathrm{V}$ is proportional to the stroke of output rod, since the area of the master cylinder piston is constant. The PV curve indicates that the wheel cylinders pressure has a certain relationship with the stroke of electric brake booster output rod y, as shown in Figure 3. Therefore, we control the brake pressure by controlling the stroke of the output rod.

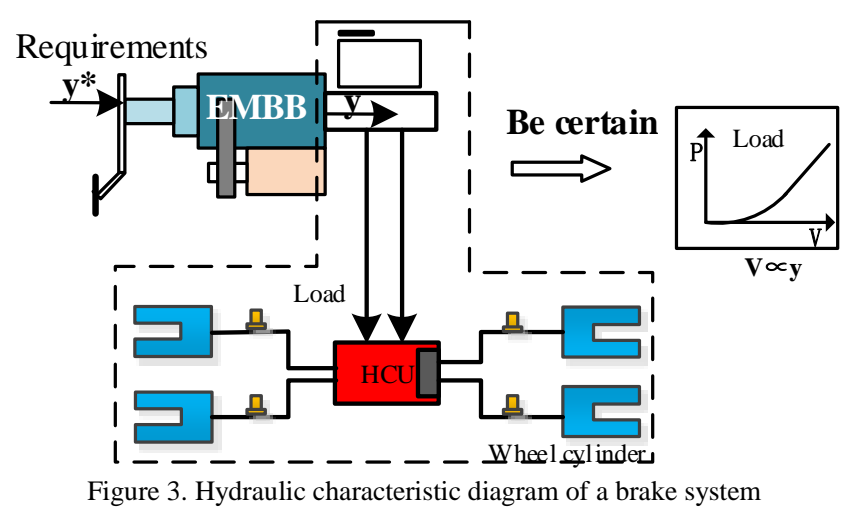

The active braking control strategy of the electronic brake system is shown in Figure 4. We translate the control problem of pressure to position. First, the conversion from the upper braking acceleration of the ADAS system to the target braking pressure is obtained. Then, in order to facilitate the control of the nonlinear system, the robust and incremental PID controller is used as the controller of the electromechanical hydraulic system [12]. Finally, based on the three closed-loop PI controller, the position tracking control of the permanent magnet synchronous motor is carried out. This is shown in Figure 4.

$$
\mathrm{u}(n-1)=k_{p}\left(e(n-1)+\frac{T}{T_{i}} \sum_{i=0}^{n-1} e(i)+\frac{T_{d}}{T}(e(n-1)-e(n-2))\right)
$$

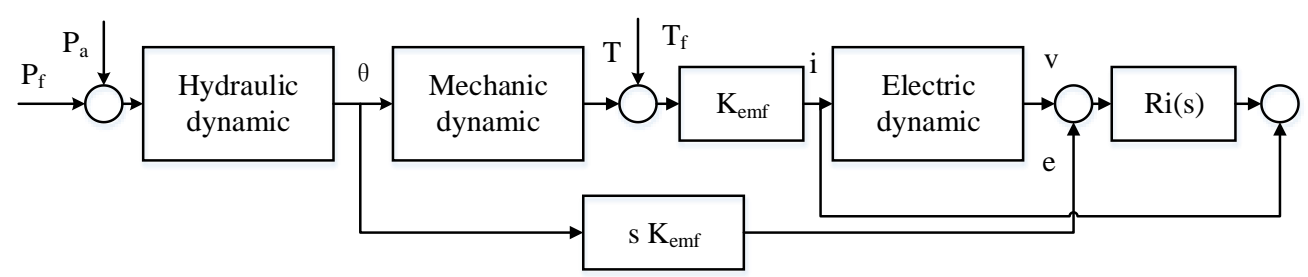

Figure 4. The active braking control strategy of the new electronic brake system

\section{Pressure-Position Tracking Controller Design}

\subsection{Precise Control Method for Wheel Cylinder Pressure}

First, the dynamic characteristics of the mechanical and electronic hydraulic system are analyzed as follows:

The electric brake booster system is mainly composed of two subsystems: the electric brake booster and the hydraulic control unit. The electric brake booster subsystem includes a PMSM, a pinion, a gear, a ball screw, and a servo body. The dynamic equations of the permanent magnet synchronous motor and the transmission mechanism are analyzed as follows. A PMSM is composed of three phase's stator winding and permanent magnets mounted on the rotor surface (the surfacemounted PMSM). Duo to the coupling between magnetic flux linkage and torque, the mathematic model of PMSM is decoupled by the d-q reference frame [13]. The PMSM voltage balance equation of the armature circuit is given as

$$
u_{d}=R i_{d}+L_{d} \frac{\mathrm{d}}{\mathrm{d} t} i_{d}-\dot{\theta}_{m} L_{q} i_{q}
$$




$$
u_{q}=R i_{q}+L_{q} \frac{\mathrm{d}}{\mathrm{d} t} i_{q}+\dot{\theta}_{m}\left(L_{d} i_{d}+\Phi_{f}\right)
$$

The electromagnetic torque equation can be described as follows considering $L_{d}=L_{q}$ in surface-mounted PMSM.

$$
T_{m}=\frac{3}{2} p_{n} \Phi_{f} i_{q}
$$

According to Newton's law, the kinetic equations of the whole system in rotational direction is

$$
T_{m}=\frac{3}{2} p_{n} \Phi_{f} i_{q}-T_{m f}-J_{m} \ddot{\theta}_{m}
$$

Where $u_{d}$ and $u_{q}$ are the voltage of the $\mathrm{d}$ and $\mathrm{q}$ axle and $\mathrm{R}$ is the resistance of stator. $i_{d}$ and $i_{q}$ are the stator currents of the $\mathrm{d}$ and $\mathrm{q}$ axle, $L_{d}$ and $L_{q}$ are the armature inductance of the $\mathrm{d}$ and q axle, $\theta_{m}$ is the motor rotational angle, $T_{m}$ and $T_{m f}$ are the output torque and friction torque, and $\Phi_{f}$ and $p_{n}$ are the flux generated by rotor permanence magnets and the number of pole pair, respectively. $J_{m}$ is the moment of inertia of the rotor. This description is similar to the dc motor with independent field excitation and simplifies the controller design of the PMSM.

The motor shaft is connected to the servo body by double reduction of the gears and screw shaft, and the servo body is connected to the reaction disk and master cylinder piston. Once the input rod moves forward or backward, the servo body moves forward or backward correspondingly under the action of the motor, providing brake assistance. Thus, the dynamic equation in translational direction is

$$
m \ddot{y}=\frac{2 \pi}{s} T_{m} k_{i}-F_{s}-F_{f}
$$

There exists the relationship between the rotational and translational movements:

$$
\theta_{\mathrm{m}}=\frac{2 \pi}{s} k_{i} y
$$

Where $\mathrm{m}$ is the mass of moving parts, $\mathrm{s}$ is the lead of screw, $F_{s}$ is the servo force, $F_{f}$ is the friction force, and $k_{i}$ is the gear ratio.

Based on the aforementioned analysis, the focus of the controller design has shifted to determining the control variable $i_{q}$ so that the PMS motor can achieve satisfactory performance in pressure-position-tracking. For the position control, some prior work on position tracking problem has followed the approach of a cascaded proportional-integral-derivative (PID) control architecture, which consists of an outer-loop position control and inner-loop motor current control. However, the strong nonlinearity and the load-dependent friction make the position control of the EMBB system more challenging. Additionally, a single set of fixed gains cannot cover the entire operational envelope satisfactorily. Consequently, in this chapter, a modified control architecture is proposed to address the plant nonlinearity with techniques of tuning gain (gain scheduling), model-based friction compensation, and inertial compensation.

As shown in Figure 5, the position tracking control of a novel electronic brake booster can be summarized by three parts. First, the target position is obtained from the target pressure through an incremental PID controller. Secondly, the strong nonlinearity and the load-dependent friction make the position tracking control of the electric brake booster more challenging. Therefore, a modified PI control architecture is presented with techniques of cascaded three closed loop PI controller, friction compensation based on friction model, and gain scheduling. The total reference current is the sum of the two terms $I^{*}=i_{q c 1}+i_{q r e f}+i q e f$. The third part is the controlled object and hydraulic load.

As mentioned earlier, we translate the control problem of the pressure control to position tracking. Position tracking control of the permanent magnet synchronous motor is mainly a three closed-loop control. As shown in Figure 6, the control strategy can be divided into three parts: the basic PMSM controller, current distribution, and current compensation decoupling. 


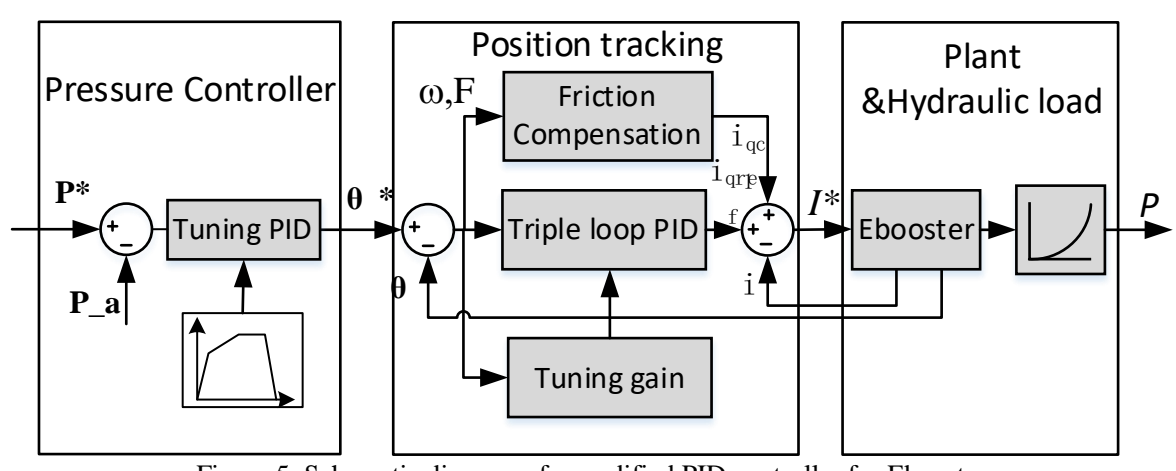

Figure 5. Schematic diagram of a modified PID controller for Ebooster

For position control of the PMSM, some prior work has followed the approach of a cascaded proportional-integralderivative (PID) control architecture, which consists of outer-loop position control and inner-loop motor current control. However, the strong nonlinearity and the load-dependent friction make a single PI controller unable to carry the entire operational envelope. Therefore, to solve the above problems, we add a feedforward compensation module to the original basic controller.

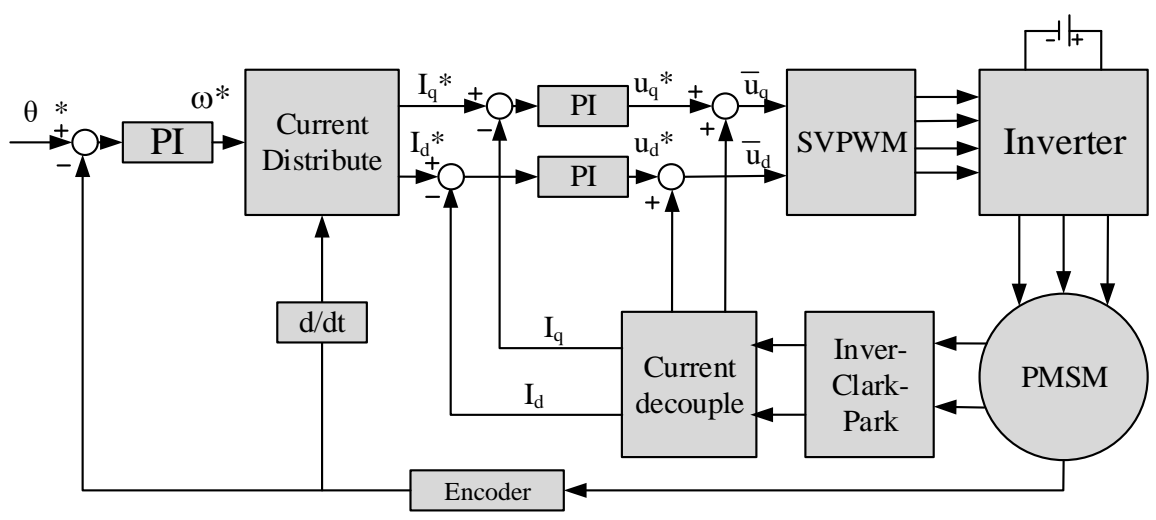

Figure 6. The control strategy of permanent magnet synchronous motor

\subsection{Test Results of Active Brake Pressure Control}

Based on the above pressure control method, to realize the active braking condition verification of the ACC cruise control and the automatic emergency brake of the intelligent driving vehicle, the sinusoidal following condition, the step following condition, and the continuous step following condition test of the target pressure are designed. The results of the test are as follows.

Figure 7 is the result of the sinusoidal following of the target pressure. To better describe the changes of pressure under the speed cruise control mode in the ADAS system, we designed target pressures of $1 \mathrm{~Hz}$ and $2 \mathrm{~Hz}$. The experimental results show that the maximum pressure tracking error is $0.8 \mathrm{bar}$, which meets the requirements of cruise control's braking follow. Figure 7 (b) and (B) show the corresponding motor position curve and Figure 7 (c) and (C) show the current tracking result of axis q. We can observe that the tracking controller performs well. Meanwhile, changes in the motor position verify the corresponding relationship between PV characteristics and the pressure control process.

Figure 8 is the step following results of the target pressure. The purpose is to verify the response speed in the case of automatic emergency braking. As can be seen in Figure 8 (a), in the case of braking deceleration of $0.8 \mathrm{~g}$ or full braking, $172 \mathrm{~ms}$ are required for the electronic brake booster to produce 70 bar of braking pressure, which is about $200 \mathrm{~ms}$ less than the traditional ESC. For example, when the vehicle makes an emergency braking of $60 \mathrm{~km} / \mathrm{h}$, the moving distance is reduced by about $2 \mathrm{~m}$ compared to the ESC system. Therefore, the response speed of the automatic emergency brake is improved. 

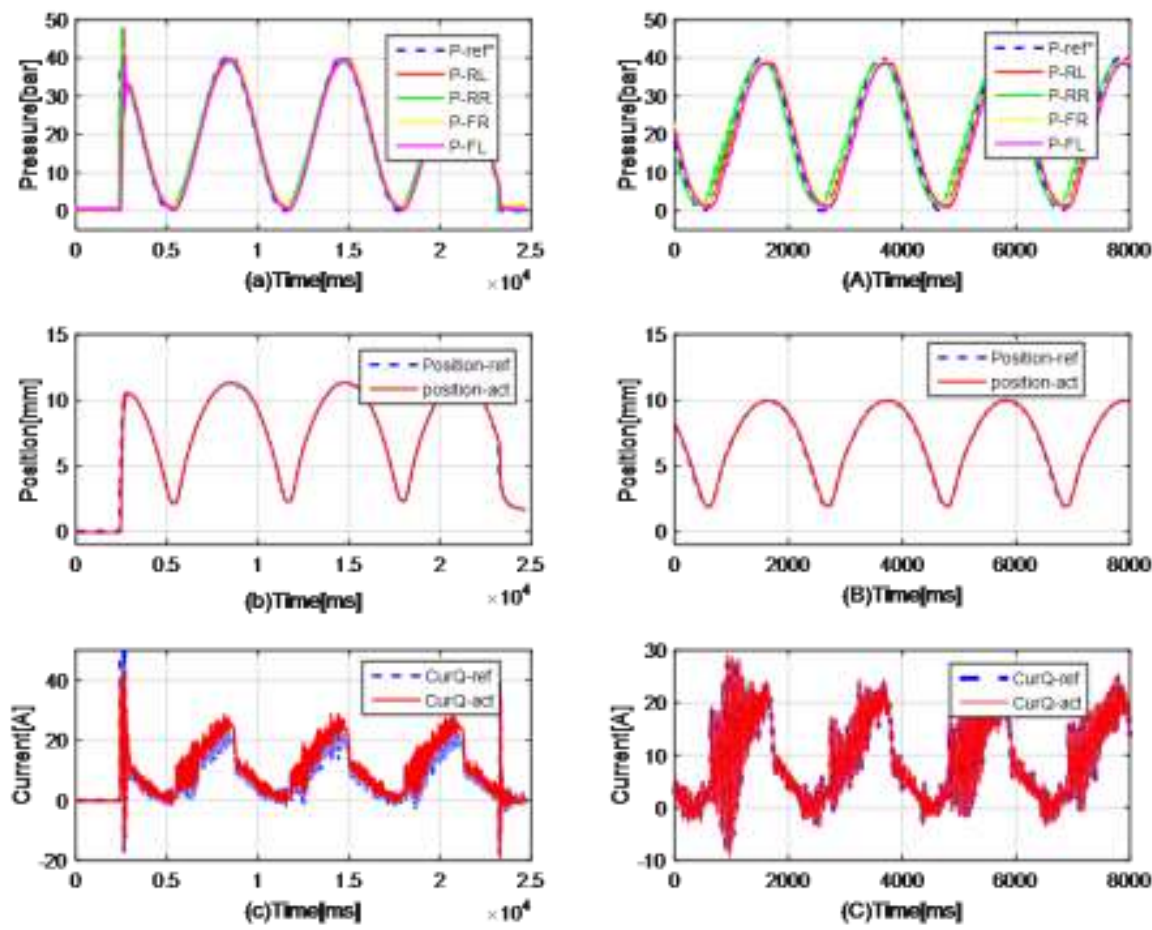

Figure 7. The results of the sinusoidal pressure following
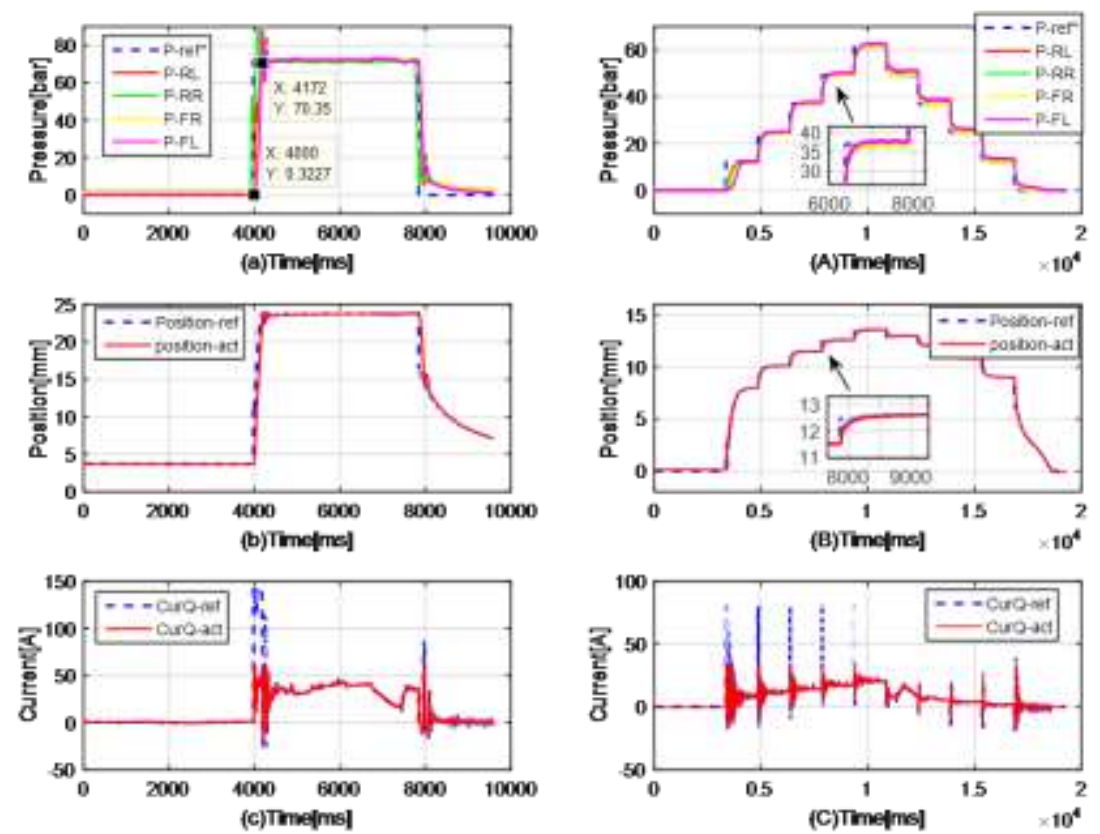

Figure 8. The results of the step target pressure following

\section{Hardware in Loop Verification}

To verify the active braking performance of the electronic brake booster and the proposed pressure control method, the braking system in the loop verification test is carried out. This is shown in Figure 9. 


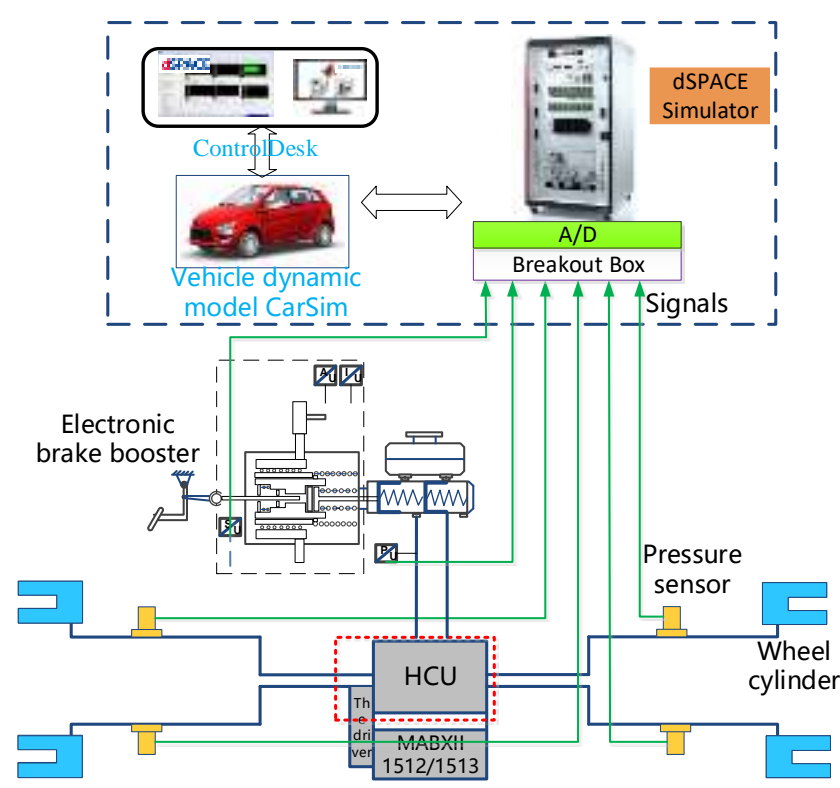

Figure 9. The hardware in the loop platform

The test platform includes the CarSim vehicle dynamics model, ACC controller based on Simulink, dSPACE-simulator real-time platform, Ebooster actuator, and so on. The control architecture adopted is the conventional stratified control, including the environment perception, the planning decision and the control execution. In the environmental perception part, the radar sensor with CarSim is used to obtain the target. The planning decision is mainly for the distance control and the speed following control. The control execution layer is the basic control of vehicle longitudinal dynamics.

\subsection{Inverse Model of the Brake System}

The hardware in the loop test is carried out at full speed ACC mode, as shown in Figure 9. In the process of active braking, the controlled vehicle has been in a straight running state, so the longitudinal dynamic control model of the controlled vehicle along its direction is considered. At the same time, the vehicle dynamic model and the road environment model are set up in Carsim. Because the model is established in the ideal simulation environment, the inverse model of the brake system and the drive system satisfies the requirements fully [14].

The dynamic equation of vehicle braking process is

$$
\mathrm{m} a_{x}=\left(\sum_{i=1}^{4} F_{x i}+\sum_{i=1}^{4} F_{f i}+F_{w}+F_{i}\right)
$$

Where $F_{x i}$ is the ground brake force of a single wheel, $F_{f i}$ is the rolling resistance of a single wheel, $F_{w}$ and $F_{i}$ are the air resistance and ramp resistance respectively, and

$$
F_{x i}=\min \left(F_{\psi \max }, \frac{T_{f}}{r}\right)
$$

The wheel braking torque can be obtained according to the braking efficiency factor.

$$
\begin{gathered}
T_{f}=P_{b} \cdot K_{b} \\
K_{b}=2 \cdot u \cdot r \cdot A
\end{gathered}
$$

Where $K_{b}$ is the brake efficiency factor, $P_{b}$ is the braking pressure in the brake wheel cylinder. $\mathrm{U}$ is the friction coefficient between the brake caliper and the brake disc, and $r$ is the distance from the center of the wheel cylinder to the 
center of the brake disc.

Therefore, the relationship between the braking acceleration and the brake pressure could be described as

$$
a_{x}=\frac{\left(\sum_{i=1}^{4} \min \left(\frac{2 \cdot u \cdot r \cdot A \cdot P_{b}}{r}, F_{\psi \max }\right)+\sum_{i=1}^{4} F_{f i}+F_{w}+F_{i}\right)}{m}
$$

\subsection{Test Results}

In the hardware-in-the-loop verification tests of accurate pressure control, the speed control conditions at different decelerations are designed.

Figure 10 shows the slow down controlling with sinusoidal acceleration.
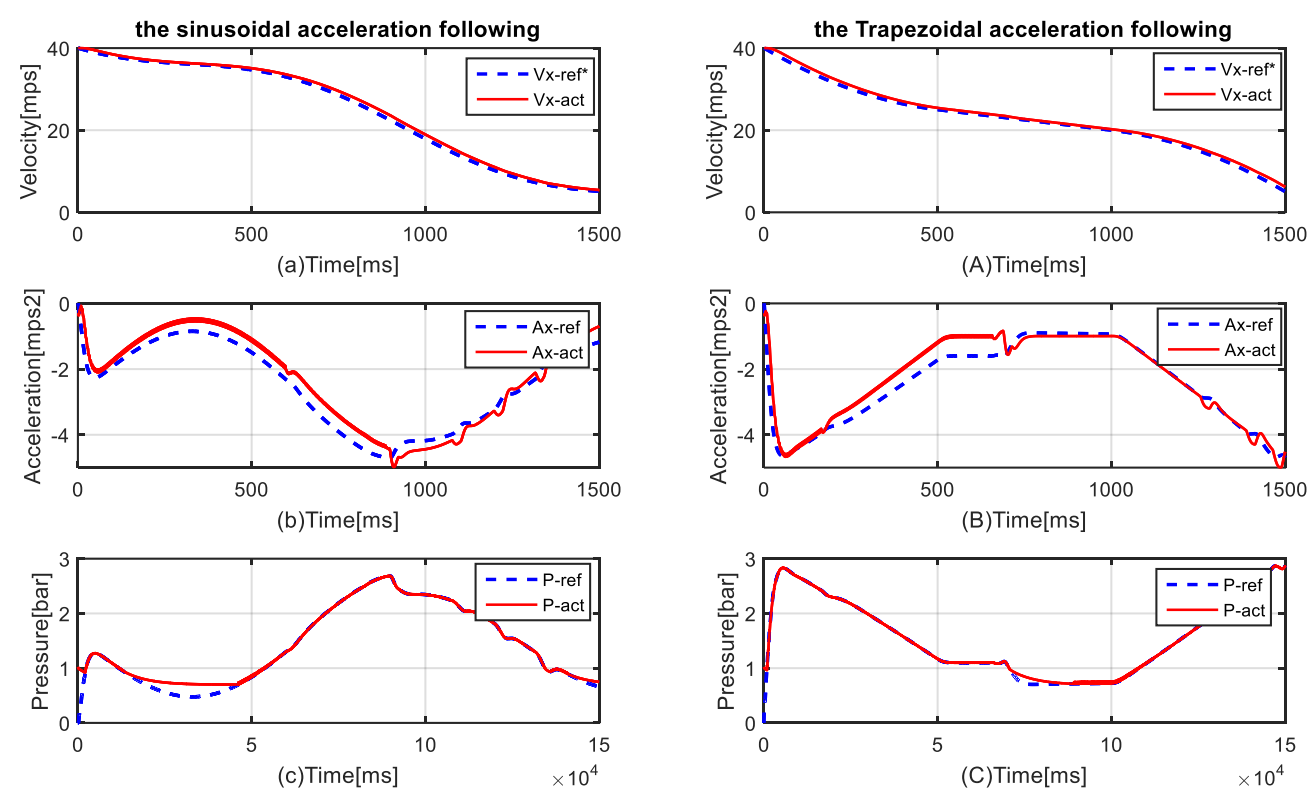

Figure 10. The results of the sinusoidal and trapezoidal acceleration following

Figure 10 (a), (b), and (c) are the test results of speed following, acceleration following, and brake pressure following. It can be observed from the experimental results that in the process of pressure following, the designed controller can meet the target requirements effectively. Even though the acceleration contains certain fluctuations and errors, the speed following error is maintained within $1.5 \mathrm{~m} / \mathrm{s}$, and the speed is satisfied.

Figure $10(\mathrm{~A}),(\mathrm{B})$, and (C) show the speed control effect of the trapezoidal acceleration. From the experimental results, we can observe that the pressure control accuracy in the entire braking process is within 0.5 bar, and the speed control effect performs well. Thus, for the intelligent automobile, the Ebooster is an active brake actuator with good performance. Cooperating with the vehicle electronic stabilization program, it provides a highly reliable and highly fault-tolerant active safety system in chassis.

\section{Conclusions}

The intelligent vehicle is an important direction for future automobile development, as it puts forward higher requirements for the structure and function of automobiles. For intelligent driving or auxiliary driving vehicles, active braking is an important and necessary function. In this paper, a novel electronic brake booster and an accurate pressure control method for engineering are put forward and consider the shortcomings of the existing braking system without active braking or insufficient performance. Such an electric brake booster system is mainly composed of a permanent magnet synchronous motor, a two-stage reduction transmission (gears and a ball screw), a servo body, and a reaction disk. It can complete two working modes: active braking for automatic drive and passive braking for driver intervention. We translate the control 
problem of pressure to position tracking for wheel cylinder pressure control. However, the strong nonlinearity and the loaddependent friction make the position tracking control of the electro-mechanical brake booster more challenging. Consequently, a modified PI control architecture is presented with techniques of cascaded three closed loop PI controller, friction compensation based on the friction model, and gain scheduling. Finally, based on dSPACE, we carried out the rapid prototyping test of active braking and the application of hardware in the loop test at full speed ACC operating conditions. The results show that pressure control, acceleration control, and speed control achieve optimal performance.

\section{Acknowledgements}

The authors wish to acknowledge the support of the National Nature Science Foundation of China under Grant 51605185.

\section{References}

1. T. Lee, T. Kim, B. Kim, and K. Yi, "Advanced Braking Algorithm for Robust Longitudinal Risk Management," in Proceedings of the Institution of Mechanical Engineers Part D-Journal of Automobile Engineering, Vol. 230, pp. 1488-1503, 2016

2. A. Forth, "Electronic Braking Systems Intelligence Service," Aroq-Just-Auto, 2013

3. B. Eichhorn, S. König, and T. Ullrich, "Electronic Brake Control for Greater Active Safety," ATZ Worldwide, Vol. 116, pp. 5053,2014

4. S. Qi, "Research on Hybrid Brake System and its EBD/ABS Control," 2016

5. N. Willi, G. Remy, "Transmission Device and Electromotive Brake Booster," 2015

6. Continental Focuses on Faster Braking with Electrohydraulic System - SAE International (http://articles.sae.org/10757/)

7. T. Oshima, N. Fujiki, S. Nakao, T. Kimura, Y. Ohtani, and K. Ueno, "Development of an Electrically Driven Intelligent Brake System," SAE International Journal of Passenger Cars - Mechanical Systems, Vol. 4, pp. 399-405, 2011

8. H. Yeo, C. Koo, W. Jung, D. Kim, and J. S. Cheon, "Development of Smart Booster Brake Systems for Regenerative Brake Cooperative Control," in Proceedings of Conference on SAE 2011 Annual Brake Colloquium and Engineering Display, September 2011

9. C. Line, C. Manzie, and M. C. Good, "Electromechanical Brake Modeling and Control: From PI to MPC," IEEE Transactions on Control Systems Technology, Vol. 16, pp. 446-457, 2008

10. H. Liu, R. He, J. Wu, W. Sun, and B. Zhu, "Linear Electro-Magnetic Valve Characteristic Analysis and Precise Pressure Control of the Electro-Hydraulic Brake System," in Proceedings of Conference on SAE 2016 World Congress and Exhibition, 2016

11. F. Todeschini, M. Corno, G. Panzani, and S. M. Savaresi, "Adaptive Position-Pressure Control of a Brake by Wire Actuator for Sport Motorcycles," European Journal of Control, Vol. 20, pp. 79-86, 2014

12. X. Feng and M. Xu, "The Applied Research of the Electric Curtain Control System based on the Fuzzy Increment PID Control Algorithm," in Proceedings of 2016 3rd International Conference on Informative and Cybernetics for Computational Social Systems, New York, 2016

13. M. Marufuzzaman, M. B. I. Reaz, F. R. Labonnah, and T. G. Chang, "High-Speed Current dq PI Controller for Vector Controlled PMSM Drive," The Scientific World Journal, 2014

14. J. Moreno-Valenzuela, Y. Quevedo-Pillado, R. Pérez-Aboytes, and L. González-Hernández, "Lyapunov-based Adaptive Control for the Permanent Magnet Synchronous Motor Driving a Robotic Load," Journal of Circuits Systems \& Computers, Vol. 26, pp. 1750168, 2017

Jian Wu is an Associate Professor of the College of Automotive Engineering at Jilin University. His research interests are mainly vehicle traction control systems, electric vehicles, and advanced vehicle control systems. He is the author of over 20 peer-reviewed papers in international journals and conferences, and he has led numerous projects on electric vehicles and energy management that were funded by the national government and institutional organizations. 